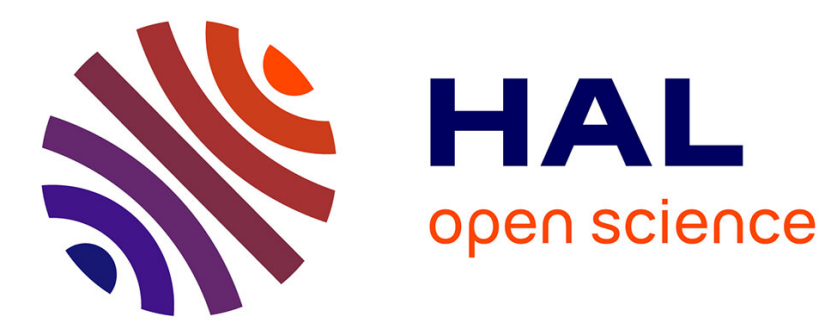

\title{
Resistivity of Manganite Thin Film Under Strain
}

G. Ovsyannikov, T. Shaikhulov, V. Shakhunov, Vladimir Preobrazhensky, T.

Mathurin, Nicolas Tiercelin, Philippe Pernod

\section{To cite this version:}

G. Ovsyannikov, T. Shaikhulov, V. Shakhunov, Vladimir Preobrazhensky, T. Mathurin, et al.. Resistivity of Manganite Thin Film Under Strain. Journal of Superconductivity and Novel Magnetism, 2019, 10.1007/s10948-019-5026-3 . hal-02127941

\section{HAL Id: hal-02127941 \\ https://hal.science/hal-02127941}

Submitted on 10 Oct 2020

HAL is a multi-disciplinary open access archive for the deposit and dissemination of scientific research documents, whether they are published or not. The documents may come from teaching and research institutions in France or abroad, or from public or private research centers.
L'archive ouverte pluridisciplinaire HAL, est destinée au dépôt et à la diffusion de documents scientifiques de niveau recherche, publiés ou non, émanant des établissements d'enseignement et de recherche français ou étrangers, des laboratoires publics ou privés. 


\title{
Resistivity of Manganite Thin Film Under Strain
}

\author{
G. A. Ovsyannikov ${ }^{1}$, T. A. Shaikhulov ${ }^{1}$, V. A. Shakhunov ${ }^{1}$, V. L. Preobrazhensky ${ }^{2}$, T. Mathurin ${ }^{3}$, \\ N. Tiercelin ${ }^{3}$ and P. Pernod ${ }^{3}$ \\ 1 Kotel'nikov Institute of Radio Engineering and Electronics, RAS, Moscow, Russia 125009 \\ 2 Prokhorov General Physics Institute RAS, Moscow, Russia 119991 \\ 3 Univ. Lille, CNRS, Centrale Lille, ISEN, Univ. Valenciennes, UMR 8520 - IEMN, F-59000 Lille, \\ France
}

\begin{abstract}
A complex study of the electron transport and magnetic characteristics of epitaxial manganite films $\mathrm{La}_{0.7} \mathrm{Ba}_{0.3} \mathrm{MnO}_{3}$ (LBMO) was carried out under conditions of the crystal structure tension caused by a mismatch between the parameters of the LBMO crystal and the substrate. The epitaxial thin films with the thickness $40-100 \mathrm{~nm}$ were grown by pulsed laser deposition at $\mathrm{T}=700-800{ }^{\circ} \mathrm{C}$ in pure oxygen pressure $0.3-1$ mbar. The substrates (110) NGO, (001) STO, (001) LAO, and (001) LSAT were used. By comparison of the lattice parameter of LBMO targets with substrate's one, the lattice mismatches were derived. We used substrates in which the lattice parameter was less than for the LBMO crystal one. It is shown that the temperature dependence of the film resistance in the low-temperature region does not depend on the film stress and is in good agreement with the calculation that takes into account the interaction of carriers with magnetic excitations in the presence of strongly correlated electron states. A nonmonotonic temperature dependence of the resistance of an LBMO film deposited on ferroelectric crystals PMN-PT that was observed. This feature is typical for manganites, and indicating the presence of ferromagnetism in the system was observed.
\end{abstract}

Rare earth manganite with perovskite structure $\mathrm{Re}_{1-\mathrm{x}} \mathrm{A}_{\mathrm{x}} \mathrm{MnO}_{3}(\mathrm{Re}$-rare earth elements such as $\mathrm{La}$ or $\mathrm{Nd}$ and $\mathrm{A}$ - alkaline earth metals such as $\mathrm{Sr}, \mathrm{Ca}, \mathrm{Ba}$ ) exhibits a wide range of unusual electrical and magnetic properties (see, for review [1]). The parameters of epitaxial films of these materials very often differ significantly from the properties of single crystals. As it has been shown in several studies $[1,2]$, the tension of the films due to mismatch with the substrate is the reason for the change in the electric and magnetic parameters of the films. It was shown that the three-dimensional compression of the crystal lattice increases the hopping probability amplitude in the double exchange model, which leads to an increase in the Curie temperature $\left(\mathrm{T}_{\mathrm{C}}\right)$, while the biaxial distortions of the Jahn-Teller type cause an increase in the localization of the electrons and decrease $\mathrm{T}_{\mathrm{C}}[3,4]$.

Manganite films, for which $\mathrm{T}_{\mathrm{C}}$ is close to room temperature, are particularly attractive for practical applications. The ferromagnetic phase transition for a $\mathrm{La}_{0.7} \mathrm{Ba}_{0.3} \mathrm{MnO}_{3}(\mathrm{LBMO})$ crystal occurs at $\mathrm{T}_{\mathrm{C}}=345 \mathrm{~K}$ [5]. In the LBMO crystal, a fairly large magnetostriction (up to $4 \times 10^{-4}$ ) was observed at a temperature equal to the Curie temperature [6]. The magnetic and resistive properties of LSMO films have been studied in a number of works [2, $5,6,7,8,9,10,11,12,13,14,15,16]$. Usually, substrates from $\mathrm{SrTiO}_{3}$ (STO) $[9,13,14,15]$ were used. The film tension was changed either by changing the thickness of the LBMO film, or by changing the ratio of $\mathrm{La}$ and $\mathrm{Ba}$. It was shown that in addition to the substrate-induced strain, oxygen content plays a very important role in determining the transport and magnetic properties of $\mathrm{La}_{1-x} \mathrm{Ba}_{x} \mathrm{MnO} 3$ thin films [9]. For correct comparison of the effect of the stress on the film properties either film deposited on the different substrate under the same conditions [2], or piezo substrate are used $[17,18]$. In LBMO films, when the film tension changes in piezo substrate, multiple resistive states arise. They are modulated by the magnetic field in a wide 
temperature range $[17,18]$. In this paper, the influence of the film stress on the resistive properties of the LBMO film either by changing the substrate or using piezo substrate are investigated.

Epitaxial LBMO films of 40-150 nm thick were deposited on either (001) $\mathrm{LaAlO}_{3}$ (LAO), (001) $\mathrm{SrTiO}_{3}$ (STO), (110) $\mathrm{NdGaO}_{3}(\mathrm{NGO}),(001)\left(\left(\mathrm{LaAlO}_{3}\right)_{0.3}+\left(\mathrm{Sr}_{2} \mathrm{AlTaO}_{6}\right)_{0.7}\right)(\mathrm{LSAT})$, or $0.79 \mathrm{~Pb}\left(\mathrm{Mg}_{1 / 3} \mathrm{Nb}_{2 / 3}\right) \mathrm{O}_{3}-0.21 \mathrm{PbTiO}_{3}(\mathrm{PMN}-\mathrm{PT})$ substrates by pulsed laser deposition at temperature of $600-800{ }^{\circ} \mathrm{C}$ under an oxygen pressure of $0.2-0.5$ mbar. A stoichiometric composition of the target was used for the growth of epitaxial films.

The $c$-axis of LBMOs films grown on "simple" substrates (LAO, STO, NGO, and LSAT) is oriented along the normal of the plane of the substrate. The interplane distance in LBMO films along the normal to substrate $a_{\perp}$ and the lattice constant of the substrate $a_{s}$ are determined by $2 \theta / \omega$ x-ray diffraction scan $[2,19,20]$. XRD $2 \theta / \omega$ scan for LBMO/LAO films is presented in Fig. 1. We consider the unit cell of the substrate as pseudocubic one. A biaxial stress in the plane of the substrate leads to the distortion of the crystal lattice of the films in the perpendicular direction [7]. Consequently, the grown manganite films are under the influence of mechanical stresses caused by interaction with the substrate.

The values of the in-plane and out of plane strains $\varepsilon_{\|}=\left(a_{\|}-a_{L B M O}\right) / a_{L B M O}$ and $\varepsilon_{\perp}=\left(a_{\perp}-a_{L B M O}\right) / a_{L B M O}$ arising in all investigated films where $a_{L B M O}=0.39 \mathrm{~nm}$ along with metal-insulator transition temperature $\mathrm{T}_{\mathrm{M}}$ are presented in Table 1 .

At small lattice distortions, the Curie temperature $\left(\mathrm{T}_{\mathrm{C}}\right)$ and other magnetic transport parameters of the manganite films depend on two parameters: the relative change in the unit cell volume $\varepsilon_{b}=2 \varepsilon_{\|}+\varepsilon_{\perp}$, that is equal to $\varepsilon_{b}=0.07$ for $\mathrm{LBMO} / \mathrm{LAO}$, and biaxial distortion $\varepsilon^{*}=\left(\varepsilon_{\perp}-\varepsilon_{\|}\right) \sqrt{ } 2 / 3=0.14$. The volume distortions of the lattice lead to an increase or decrease in $\mathrm{T}_{\mathrm{C}}$, depending on the sign of the distortion. The biaxial ones always cause a decrease in $\mathrm{T}_{\mathrm{C}}[8$, $18]$.

The highest value of temperature of metal-insulator transition $\mathrm{T}_{\mathrm{M}}=283 \mathrm{~K}$ was observed for LBMO films grown on STO substrates (see Fig. 1). However, even in the case of a small misalignment of the substrate and the film, when the in-plane strain is equal to $\varepsilon_{\|}=-0.13 \%$, the temperature $T_{M}$ of the film is of several degrees lower than the values for stoichiometric LBMO single crystals. It is possible that the decrease in $T_{M}$ is due to the relatively low concentration of carriers in LBMO films caused by a decrease in $\mathrm{Ba}$ [7].

At temperature $\mathrm{T}<\mathrm{T}_{\mathrm{M}}$, according to $[10,21,22]$, the temperature dependence of the resistance of the manganite film can be represented in the form

$$
\rho=\rho_{0}+\rho_{1} T^{2}+\rho_{2} T^{4.5}
$$

where $\rho_{0}$ is the contribution to the resistance due to structural defects, $\rho_{1}$ is determined by electron-electron scattering, and $\rho_{2}$ is caused by the scattering of electrons by magnons.

The smallest value $\rho_{0}=2.3 \times 10^{-3} \Omega \mathrm{cm}$ is observed for LBMO/STO films that were grown on STO substrates having the smallest mismatch between their crystal lattice of the substrate and the film $(-0.13 \%)$. The obtained $\rho_{0}$ are several times greater than for single crystals [23]. This increase of $\rho_{0}$ in LBMO/LAO film could be due to twinning of the substrate, which leads to a 
broadening of the rocking curve. The dependence $\rho \infty \mathrm{T}^{4.5}$ was indeed observed for manganite films $\mathrm{La}_{0.67} \mathrm{Ba}_{0.33} \mathrm{MnO}_{3}$ deposited on the (001) LSAT substrate [10]. At the same time, the dominance of the $\mathrm{T}^{2}$ term was observed in LSMO films [2]. A small increase in the value of $R(\mathrm{~T})$ at $\mathrm{T}<50 \mathrm{~K}$ can be caused by the Coulomb interaction of carriers, which contribution to the resistance is proportional to $T^{1 / 2}$ [7]. The analysis of the temperature dependences of the resistance in the temperature range $(100-250 \mathrm{~K})$ has shown that $R(\mathrm{~T})$ of LBMO/STO films is described with good accuracy by the expression (1) for $\rho_{1}=9 \times 10^{-9} \Omega \mathrm{cm} \mathrm{K}^{-2}, \rho_{2}=4$ $10^{-13} \Omega \mathrm{cm} \mathrm{K}^{-4.5}$, and $\rho_{0}=2.3 \times 10^{-3} \Omega \mathrm{cm}$. The temperature dependence of resistance at $\mathrm{T}<$ $\mathrm{T}_{\mathrm{M}}$ for the LBMO/NGO structure is shown in the inset in Fig. 2. The fitting curve Eq. (1) and the experimental data are practically indistinguishable.

We note that in the high-temperature region $\mathrm{T}>\mathrm{T}_{\mathrm{M}}$, the temperature dependence of the resistance of manganite films is determined by the activation processes [24].

Ferroelectric crystals of $0.79 \mathrm{PbMg}_{1 / 3} \mathrm{Nb}_{2 / 3} \mathrm{O}_{3}-0.21 \mathrm{PbTiO}_{3}$ (PMN-PT) used as an active substrate have a Curie temperature of $150{ }^{\circ} \mathrm{C}$ and high piezoelectric constants $d_{33}=1500 \mathrm{pC} / \mathrm{N}$, $d_{32}=-1883 \mathrm{pC} / \mathrm{N}, d_{31}=610 \mathrm{pC} / \mathrm{N}$ [25]. In PMN-PT, a transition from the cubic to the rhombohedral phase is observed at $\mathrm{T}=348 \mathrm{~K}$. The transition is accompanied by a decrease in the lattice constant from $a=0.4043 \mathrm{~nm}$ at $\mathrm{T}>600 \mathrm{~K}$ to $a=0.4036 \mathrm{~nm}$ at $\mathrm{T}<50 \mathrm{~K}[18,26,27]$. We used the substrates with orientation (011) PMN-PT.

By applying a voltage to the PMN-PT substrate, we studied the effect of the ferroelectric polarization and the inverse piezoelectric effect on the temperature dependence of the resistance and the temperature of the metal-insulator transition $\mathrm{T}_{\mathrm{M}}$ for thin LBMO films. The saturation of the ferroelectric loop for PMN-PT substrate is observed at voltages exceeding $3 \mathrm{kV} / \mathrm{cm}$. The saturation polarization is equal to $\operatorname{Pr}=320 \mu \mathrm{C} / \mathrm{cm}^{2}$. At lower sweep voltages, a particular loop is observed.

Figure 3 shows the deformation in two directions measured by a resistive strain gauge method in the plane of the substrate as a function of the voltage applied across the plane. It can be seen that the deformation of the substrate essentially depends on the measurement direction. The electric field $\pm 0.1 \mathrm{kV} / \mathrm{cm}$ does not lead to significant deformations in the (011) direction, at the same time, the deformations increase with the voltage in the $(001)$ direction for $\pm 2 \mathrm{kV} / \mathrm{cm}$. At voltages corresponding to the coercive force for ferroelectric loop, a sharp increase of deformation in the (011) direction is observed.

After the PMN-PT substrate was poled by setting the voltage $(7 \mathrm{kV} / \mathrm{cm})$ to the substrate at room temperature, we studied the influence of inverse piezoelectric effect on the metal-insulator transition temperature and on film resistance (Fig. 4).

Figure 5 shows the temperature dependence of the resistance of the LBMO film at different values of the DC voltage applied to the LBMO/PMN-PT structure before and after poling. The nonmonotonic dependence $R(\mathrm{~T})$, typical for epitaxial manganite films, is observed on LBMO films (see Fig. 2). The maximum resistance at high temperatures corresponds to the temperature of the metal-insulator transition $\mathrm{T}_{\mathrm{M}}$, which is close to the ferromagnetic transition temperature $\mathrm{T}_{\mathrm{C}}$. However, instead of a monotonously decrease $\mathrm{R}$ at low temperature, which is typical for epitaxial films, an increase of $R(\mathrm{~T})$ with decreasing of the temperature at $\mathrm{T}<50 \mathrm{~K}$ is observed. A similar behavior of $R(\mathrm{~T})$ was observed in [28] for $\mathrm{La}_{0.85} \mathrm{Sr}_{0.15} \mathrm{MnO}_{3}$ film deposited on PMNPT. The value of the strain in LBMO films deposited on (001) PMN-PT plane is equal to $\varepsilon_{\|}=\left(a_{\|}-a_{L B M O}\right) / a_{L B M O}=3.6 \%\left(a_{L B M O}=0.39 \mathrm{~nm}\right)$ before poling. A similar strain, but of an 
opposite sign, arises when the LBMO film is grown on the LAO substrate. However, a decrease of the temperature $\mathrm{T}<50 \mathrm{~K}$, leads to decrease, rather than an increase, in $R(\mathrm{~T})$. The resistivity of the LBMO/PMN-PT film demonstrates other specific features. The transition temperature $\mathrm{T}_{\mathrm{M}}=182 \mathrm{~K}$ is lower than that of LBMO/LAO (see Fig. 2).

After the poling, the dependence $R(\mathrm{~T})$ does not change significantly. The greatest relative change in resistance is observed near the temperature $\mathrm{T}_{\mathrm{M}}: \Delta R / R=5.8 \%$.

At room temperature, the changes of $\mathrm{R}$ were also observed, but much smaller in value. Figure 6 shows the resistance changes after poling when an electric field with strength $E= \pm 1.3 \mathrm{kV} / \mathrm{cm}$ is applied to the substrate. The observed hysteresis can be associated with a sharp variation of the strain in the (011) direction (see Fig. 3).

In summary, the epitaxial manganite lanthanum-barium films deposited on four types of the substrates demonstrate the effect of strain on the films resistivity. The temperature dependence of the resistivity of all films at low temperatures is well described by a power polynomial that takes into account the effect of scattering on defects and impurities as well as electron-electron and electron-magnon interactions. A nonmonotonic temperature dependence of the resistance of an LBMO film deposited on ferroelectric crystals PMN-PT is typical for manganites and indicates the presence of ferromagnetism in the system. A hysteretic dependence of the resistance of the LBMO film on the piezoelectric strain of the substrates was detected.

\section{Acknowledgments}

Acknowledgments are given to A.S. Grishin, A.A. Klimov, and A.M. Petrzhik for the help and discussion. The authors also want to thank the French RENATECH network.

\section{Funding}

This work was performed in the framework of the International Associated Laboratory LEMAC-LICS and partially supported by the RFBR grant 16-29-14022.

\section{References}

[1] Haghiri-Gosnet, A.-M., Renard, J.P.: CMR manganites: physics, thin films and devices. J. Phys. D. Appl. Phys. 36, R127-R150 (2003)

[2] Ovsyannikov, G.A., Petrzhik, A.M., Borisenko, I.V., Klimov, A.A., Ignatov, Y.A., Demidov, V.V., Nikitov, S.A.: Magnetotransport characteristics of strained $\mathrm{La}_{0.7} \mathrm{Sr}_{0.3} \mathrm{MnO}_{3}$ epitaxial manganite films. J. Exp. Theor. Phys. 108, 48-55 (2009)

[3] Lu, Y., Klein, J., Hofener, C., Wiedenhorst, B., Philipp, J.B., Herbstritt, F., Marx, A., Alff, L., Gross, R.: Magnetoresistance of coherently strained $\mathrm{La}_{2 / 3} \mathrm{Ba}_{1 / 3} \mathrm{MnO}_{3} / \mathrm{SrTiO}_{3}$ superlattices. Phys. Rev. B. 62, 15806-15814 (2000)

[4] Millis, A.J., Darling, T., Migliori, A.: Quantifying strain dependence in "colossal" magnetoresistance manganites. J. Appl. Phys. 83, 1588-1591 (1998) 
[5] Ju, H.L., Gopalakrishnan, J., Peng, J.L., Qi, L., Xiong, G.C., Venkatesan, T., Greene, R.L.: Dependence of giant magnetoresistance on oxygen stoichiometry and magnetization in polycrystalline $\mathrm{La}_{0.67} \mathrm{Ba}_{0.33} \mathrm{MnO}_{3}$. Phys. Rev., B. 51, 6143 (1995)

[6] Demin, R.V., Koroleva, L.I., Muminov, A.Z., Mukovskiı̌, Y.M.: Giant volume magnetostriction and colossal magnetoresistance in $\mathrm{La}_{0.7} \mathrm{Ba}_{0.3} \mathrm{MnO}_{3}$ at room temperature. Phys. Solid State. 48, 322-325 (2006)

[7] Boikov, Y.A., Claeson, T.: Magnetoresistance anisotropy in $\mathrm{La}_{0.67} \mathrm{Ba}_{0.33} \mathrm{MnO}_{3}$ films laterally compressed by a neodymium gallate substrate. Tech. Phys. 59, 1027-1031 (2014)

[8] Orgiani P., Adamo C., Barone C., Galdi A., Pagano S., A. Yu. Petrov A. Yu., Quaranta O., Aruta C., Ciancio R., Polichetti M., Zola D. and Maritatoet L.: Epitaxial growth of La $0.7 \mathrm{Ba}$ $0.3 \mathrm{MnO}_{3}$ thin films on $\mathrm{MgO}$ substrates: structural, magnetic, and transport properties. $\mathrm{J}$. Appl. Phys., 103, 093902-1-093902-8 (2008)

[9] P. Orgiani, A. Guarino, C. Aruta, C. Adamo, A. Galdi, A. Yu. Petrov, R. Savo, and L. Maritato, Magnetotransport properties of epitaxial strain-less La0.7Ba0.3MnO3 thin films J. Appl. Phys. 101, 033904 (2007)

[10] Boikov, Y.A., Serenkov, I.T., Sakharov, V.I., Claeson, T., Kalabukhov, A., Afrosimov, V.V.: Structure and magneto-transport parameters of partially relaxed and coherently grown $\mathrm{La}_{0.67} \mathrm{Ba}_{0.33} \mathrm{MnO}_{3}$ films. Phys. Solid State. 55, 2043-2050 (2013)

[11] Boikov Yu, A., Danilov, V.A.: Electrical resistivity and magnetotransport in La0. 67Ba0. $33 \mathrm{MnO} 3$ films asymmetrically biaxially compressed by an $\mathrm{NdGaO} 3$ (001) substrate. Phys. Solid State. 50, 95-100 (2008)

[12] Bern F, Ziese M, Vrejoiu I, Li X and Avan AkenP "Magnetic and magnetotransport properties of ultrathin $\mathrm{La} 0: 7 \mathrm{Ba} 0: 3 \mathrm{MnO} 3$ epitaxial films embedded in SrRuO3" New J. Phys. 18, $053021(2016)$

[13] Liang, Y.-C.: Lattice effects in ferromagnetic La1 - xBaxMnO3 thin films. Surface \& Coatings Technology. 202, 5436-5439 (2008)

[14] Pradhan, K., Sahu, D.R., Roul, B.K., Feng, Y.: La1ÀxBaxMnO3 epitaxial thin films by pulsed-laser deposition: a consequence of strain stabilization. Appl. Phys. Lett. 81, 35973599 (2002)

[15] Zhang, J., Tanaka, H., Kanki, T., Choi, J.-H., Kawai, T.: Strain effect and the phase diagram of La1-xÀxBaxMnO3 thin films. Phys. Rev. B. 64(184404), (2001)

[16] Kanki, T., Yanagida, T., Vilquin, B., Tanaka, H., Kawai, T.: Hall effect in strained La0.85Ba0.15MnO3 thin films. Phys. Rev. B. 71, 012403-0121-3 (2005)

[17] Weiping, Z., Yuanqiang, X., Zhengming, Z., Dunhui, W., Weishi, T., Qingqi, C., Zhenghong, Q., Youwei, D.: Multilevel resistance switching memory in $\mathrm{La}_{2 / 3} \mathrm{Ba}_{1 / 3} \mathrm{MnO}_{3} / 0.7 \mathrm{~Pb}\left(\mathrm{Mg}_{1 / 3} \mathrm{Nb}_{2 / 3}\right) \mathrm{O}_{3}-0.3 \mathrm{PbTiO}_{3}(011)$ heterostructure by combined straintronics-spintronics. ACS Appl. Mater. Interface. 8, 5424-5431 (2016) 
[18] Zheng, R.K., Jiang, Y., Wang, Y., Chan, H.L.W., Choy, C.L., Luo, H.S.: Ferroelectric poling and converse-piezoelectric-effect-induced strain effects in $\mathrm{La} 0.7 \mathrm{Ba} 0.3 \mathrm{MnO} 3$ thin films grown on ferroelectric single-crystal substrates. Phys. Rev., B. 79, 174420-1-174420-7 (2009)

[19] Tsui, F., Smoak, M.C., Nath, T.K., Eom, C.B.: Strain-dependent magnetic phase diagram of epitaxial La0.67Sr0.33MnO3 thin films. Appl. Phys. Lett. 76, 172421-172423 (2000)

[20] Ovsyannikov, G.A., Shaikhulov, T.A., Shakhunov, V.A., Demidov, V.V., Andreev, N.V., Pestun, A.E., Preobrazhenskii, V.L.: Effect of the stresses caused by substrate on the electrical conductivity of ferromagnetic manganite lanthanum-barium films. Phys. Solid State. 59, 2198-2202 (2017)

[21] Kubo, K., Ohata, N.: A quantum theory of double exchange. J. Phys. Soc. Jpn. 33, 21-33 (1972)

[22] Pietambaram, S.V., Kumar, D., Singh, R.V., Lee, C.B., Kaushik, V.S.: Microstructure, magnetoresistance, and magnetic properties of pulsed-laser-deposited external, internal, and mixed-doped lanthanum manganite films. J. Appl. Phys. 86, 3317-3326 (1999)

[23] Jiang W., Zhou X. Z., , Williams G.,. Mukovskii Y., and Glazyrin K.:, Griffiths phase and critical behavior in single-crystal $\mathrm{La} 0.7 \mathrm{Ba} 0.3 \mathrm{MnO} 3$ : phase diagram for $\mathrm{La} 1-\mathrm{xBaxMnO} 3$ $(\mathrm{x} \leqslant 0.33)$. Phys. Rev. B 77, 064424-1-064424-7 (2008)

[24] Bebenin, N.G., Zainullina, R.I., Mashkautsan, V.V., Ustinov, V.V., Mukovskii, Y.M.: Electronic transport in ferromagnetic La1-xSrxMnO3 single-crystal manganites. Phys. Rev. B. 69, 104434-1-104434-9 (2004)

[25] Wang F., Luo L., Zhou D., Zhao X. and Luo H.: Complete set of elastic, dielectric, and piezoelectric constants of orthorhombic $0.71 \mathrm{~Pb}(\mathrm{Mg} 1 / 3 \mathrm{Nb} 2 / 3) \mathrm{O} 3-0.29 \mathrm{~Pb} \mathrm{Ti} \mathrm{O} 3$ single crystal Apl. Phys. Lett. 90, 212903-1212903-3 (2007)

[26] Cao H., Bai F. M., Li J. F., Viehland D.,. Xu G. Y, Hiraka H., and Shirane G., Structural phase transformation and phase boundary/stability studies of field-cooled $\mathrm{Pb}(\mathrm{Mg} 1 / 3 \mathrm{Nb} 23 \mathrm{O} 3)-32 \% \mathrm{PbTiO} 3$ crystals J. Appl. Phys., 97, 094101-1-094101-4 (2005)

[27] Slodczyk A. Structural, dielectric and vibrational studies of lead magnesium niobate-lead titanate (1-x) PbMg1/3Nb2/3O3-xPbTiO3 solid solutions Katowice (2006)

[28] Zheng R. K., Wang Y., Chan H. L.W., and Choy C. L., Luo H. S.: Strain-mediated electric-field control of resistance in the $\mathrm{La} 0.85 \mathrm{Sr} 0.15 \mathrm{MnO} 3 / 0.7 \mathrm{~Pb}(\mathrm{Mg} 1 / 3 \mathrm{Nb} 2 / 3) \mathrm{O} 3-$ 0.3PbTiO3 structure. Appl. Phys. Lett. 90, 152904-1-152904-3 (2007) 
Table 1: Obtained from XRD scan parameters for four substrates and LBMO films deposited on. The values of the in plane and out of plane strains $\varepsilon_{\|}=\left(a_{\|}-a_{L B M O}\right) / a_{L B M O}$ and $\varepsilon_{\perp}=\left(a_{\perp}-\right.$ $\left.a_{L B M O}\right) / a_{L B M O}$ correspondingly. $\mathrm{T}_{\mathrm{M}}$ in the temperature of metal-insulator transition

\begin{tabular}{lllrrr} 
Subst. & as $(\mathrm{nm})$ & $\mathrm{a}_{\perp}(\mathrm{nm})$ & $\varepsilon_{\perp}(\%)$ & $\varepsilon \|(\%)$ & $\mathrm{T}_{\mathrm{M}}(\mathrm{K})$ \\
\hline NGO & 0.386 & 0.391 & -0.20 & -0.84 & 259 \\
LAO & 0.379 & 0.393 & 0.69 & -2.79 & 278 \\
STO & 0.391 & 0.393 & 0.78 & 1.12 & 287 \\
LSAT & 0.387 & 0.396 & 1.65 & -0.64 & 256
\end{tabular}




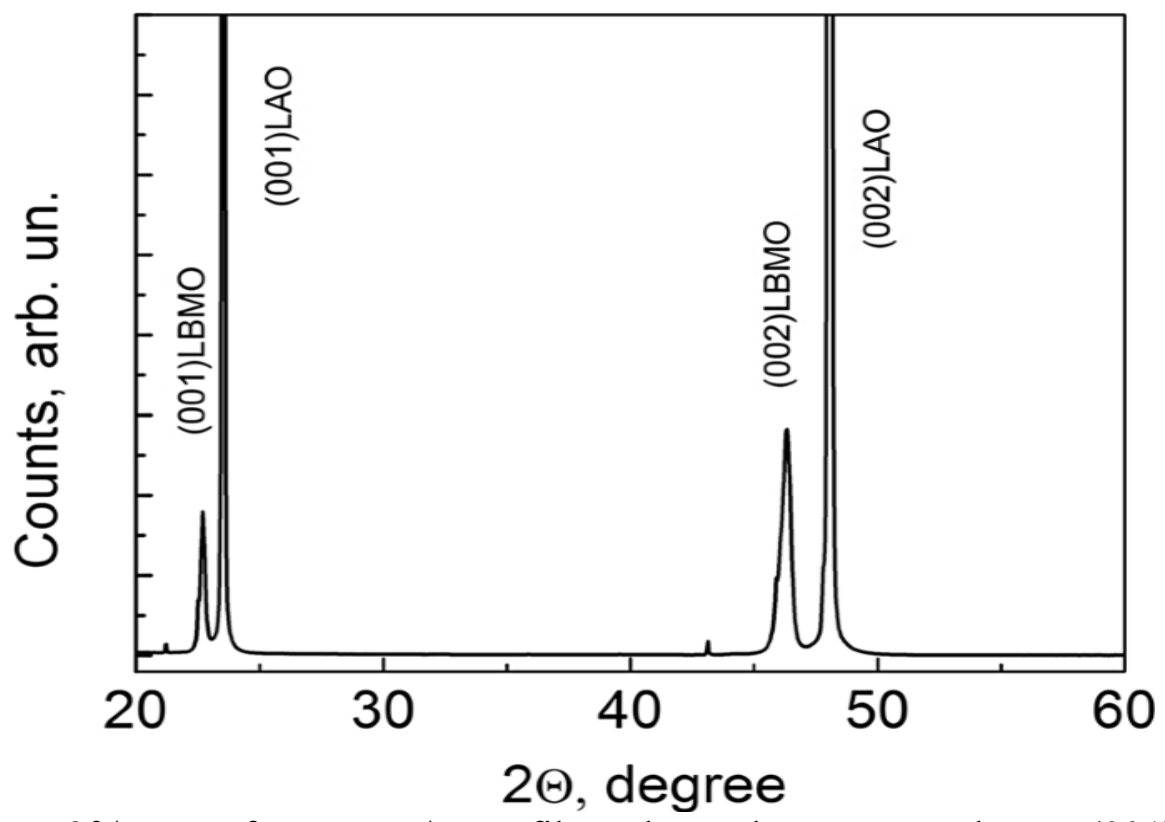

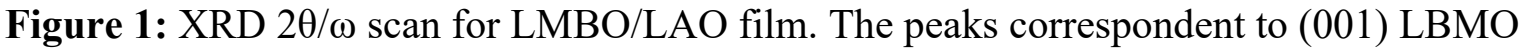
film and (001) LAO substrate are indicated in figures

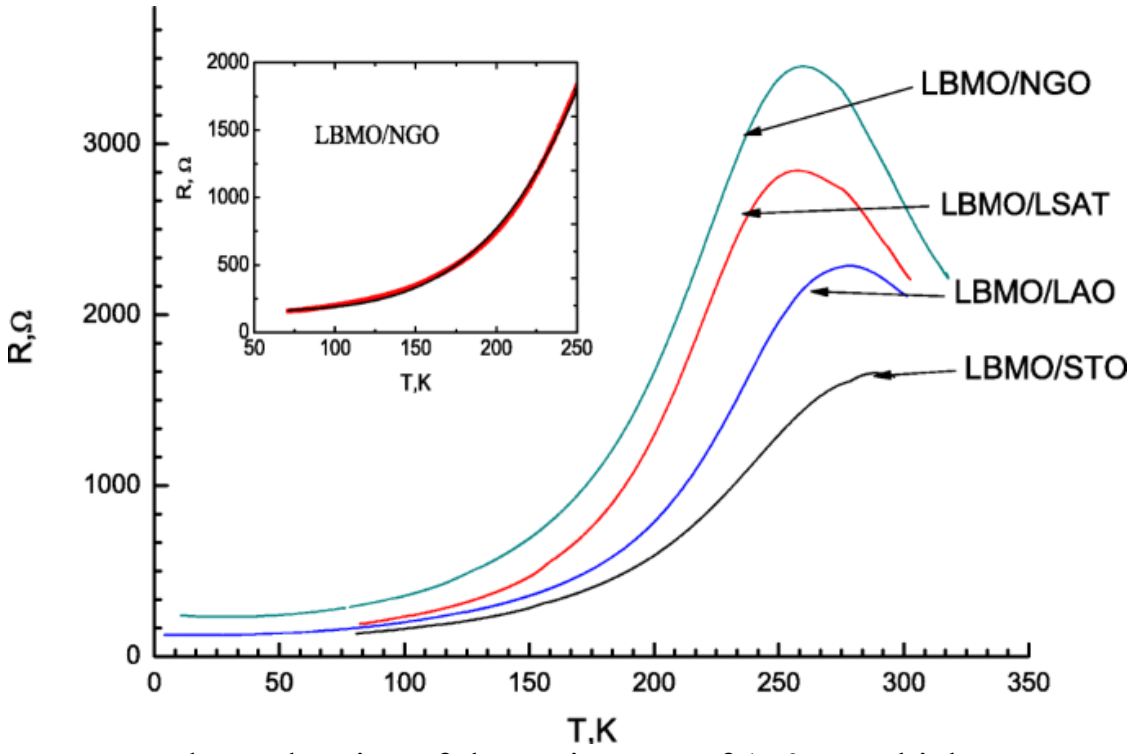

Figure 2: Temperature dependencies of the resistance of 150-nm-thick LBMO epitaxial films deposited on substrates (001) STO, (110) NGO, (001) LSAT, (001) LAO. The inset shows the $R(\mathrm{~T})$ dependence for the $\mathrm{LBMO} / \mathrm{NGO}$ structure in the temperature range $50-250 \mathrm{~K}$ and its approximation by the Eq. (1) 


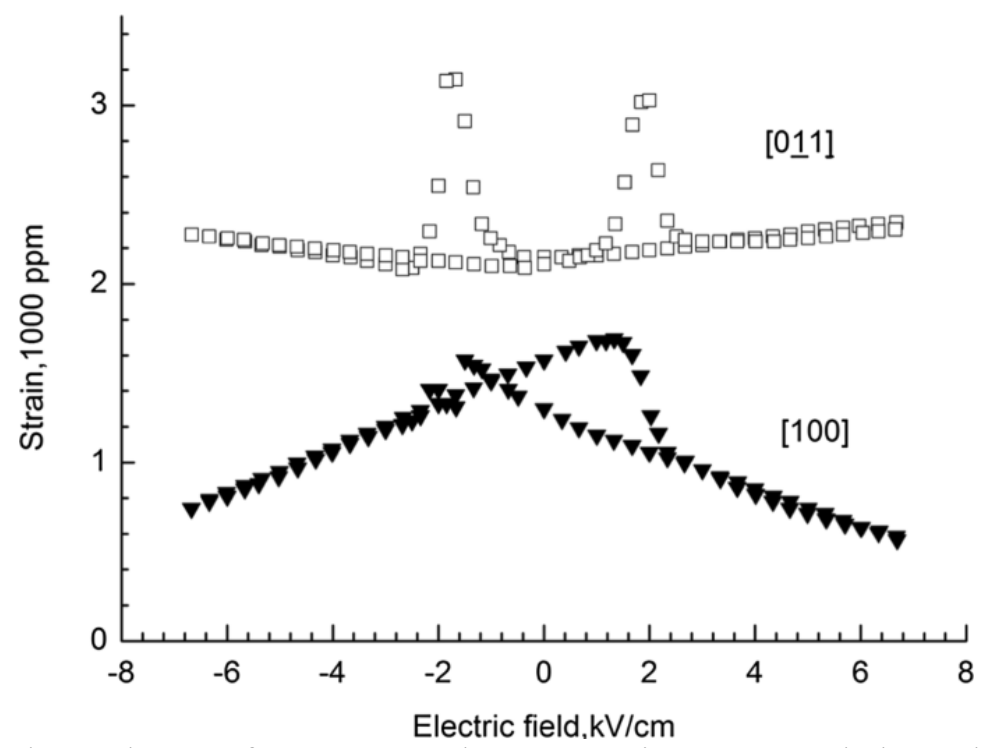

Figure 3: Voltage dependence of PMN-PT substrate strain, measured along the directions (011) PMN-PT (top) and (100) PMN-PT (bottom)

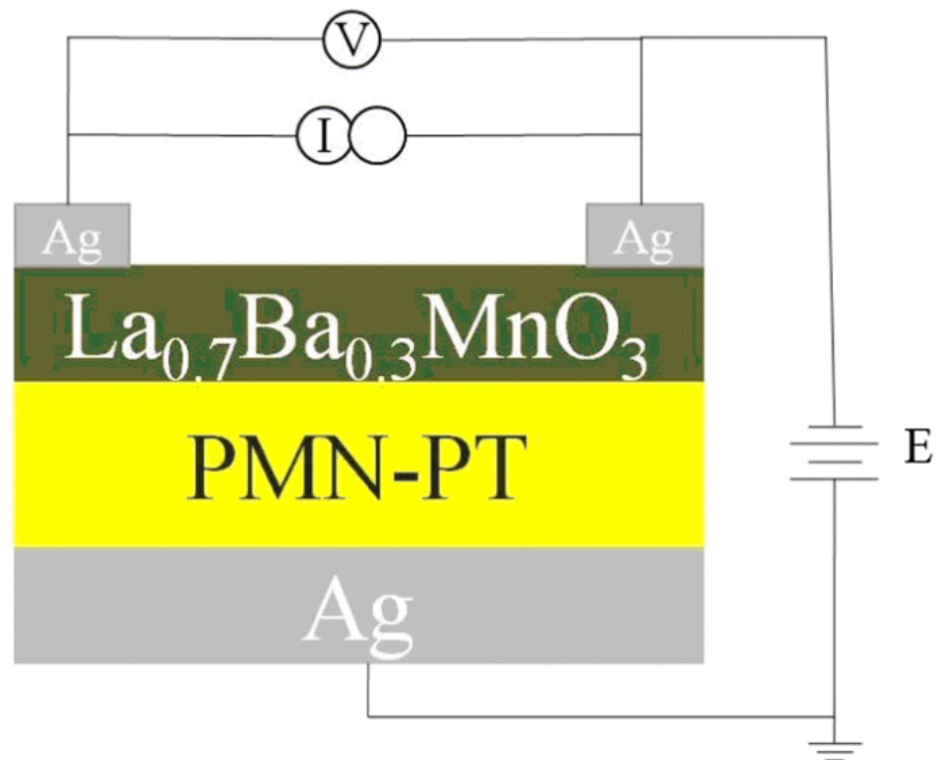

Figure 4: Schematic representation of the connection of the sample to the measuring system. I is the current source, $\mathrm{V}$ is the voltmeter. The polarization voltage is applied between the back side of the substrate covered by silver paste and the LBMO film through the contacts of silver paste. 


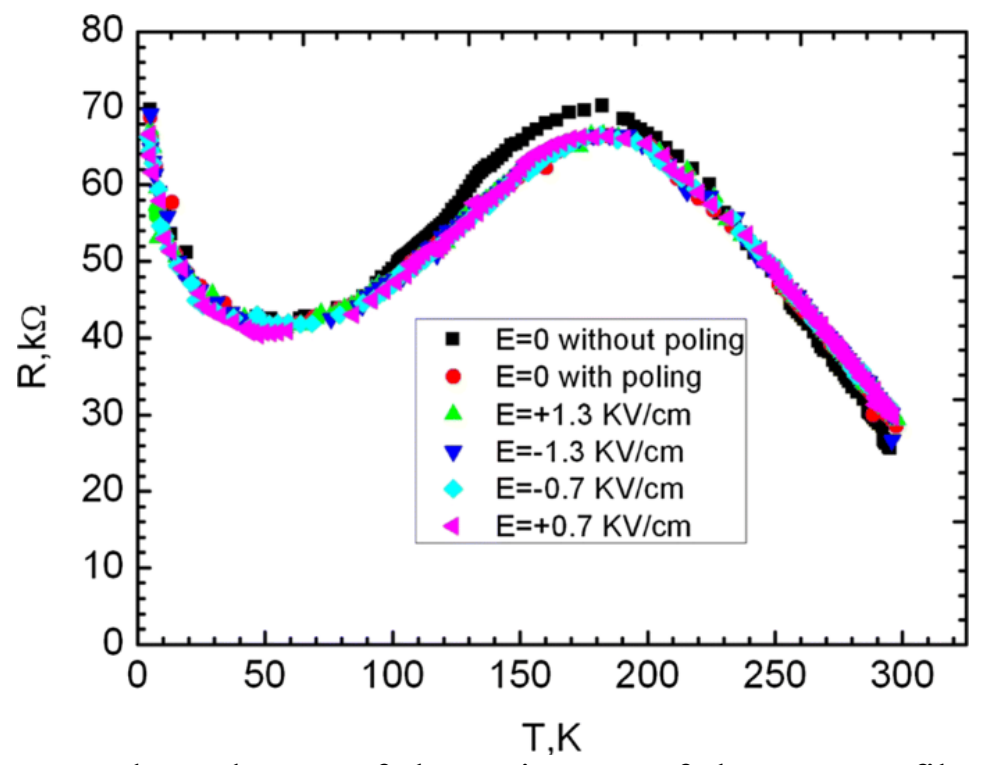

Figure 5: Temperature dependences of the resistance of the LBMO film on the electrical voltage $E$ applied across the substrate planes of PMN-PT: temperature dependences of the film resistance before polarization of the substrate at $E=7 \mathrm{kV} / \mathrm{cm}$ and after under electric field $E=0$, $\pm 0.7 \mathrm{kV} / \mathrm{cm}, \pm 1.3 \mathrm{kV} / \mathrm{cm}$

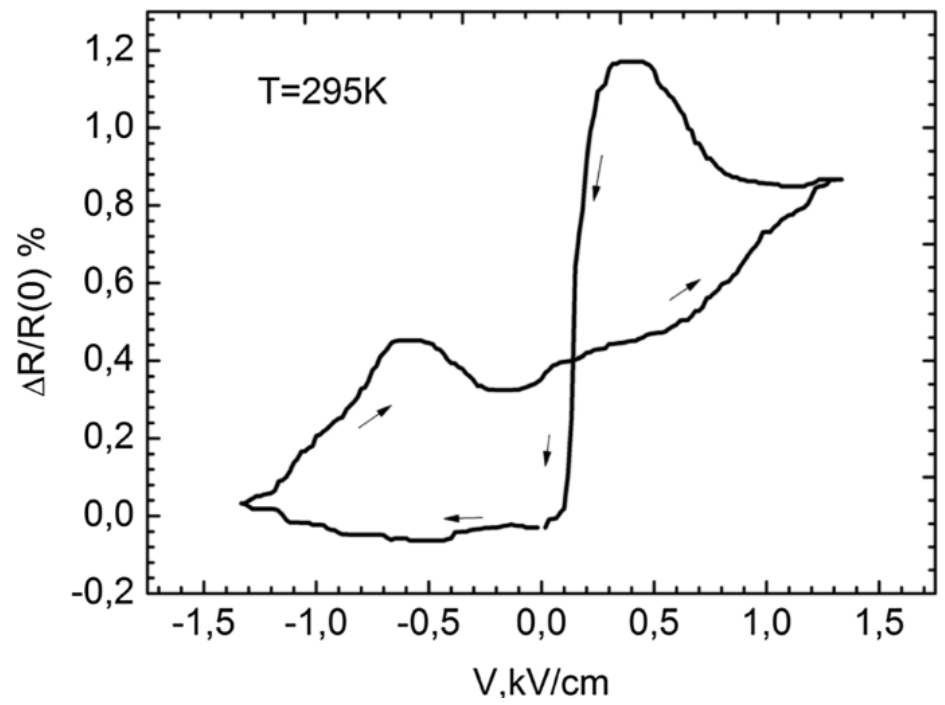

Figure 6: Dependence of the resistance of the LBMO film on the electrical voltage applied to the substrate 